\title{
Conflicting rights and the politics of privacy
}

Searching Eyes: Privacy, the State, and Disease Surveillance in America Amy L. Fairchild, Ronald Bayer and James Colgrove with Daniel Wolfe University of California Press/Milbank Memorial Fund; 2007. 342 pp \$50

$\mathrm{T}$ his riveting account of the tumultuous politics of public health privacy is a gem of a book that I have been recommending to colleagues since I first stumbled upon it. Rarely does one find such a combination of engaging narrative and well-researched scholarly annotations (neatly tucked away in more than 70 pages of notes at the back of the book).

The analysis, backed by numerous illustrative examples, allows an understanding of the progression from the emergence of the notion of the "sanctity of the private realm" in the late 19th century to the gradual strengthening of the right to personal privacy, propelled by health care and societal events, during the 20th century. In the process, the competing notions of individual and societal rights play out their struggle and what emerges are 3 legitimate rationales for breaching individual privacy: for the "commonwealth ideal" of improved delivery of health care services, for the expansion of medical knowledge and for the protection of other individuals (in the context of diseases such as tuberculosis, polio and syphilis). The authors contrast the tenants of "paternalistic privacy" with the notion of "democratic privacy," defined as the desire and ability of individuals to dictate the terms of privacy for themselves, and use it to explain how modern society handles the balance between individual and societal rights in the context of management of modern issues, such as the AIDS epidemic and child health (parental autonomy v. immunization).

The differing perspectives and roles of physicians on both sides of the debate are also explored thought-

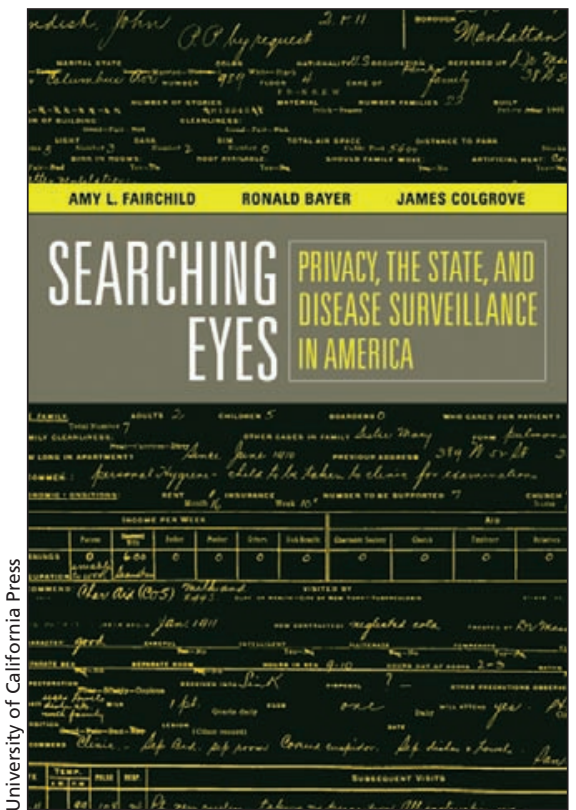

fully and impartially. The proponents of medical science and of public health protection have come into frequent conflict with their colleagues' fiduciary duty to protect the privacy of their individual patients. After all, physicians' duty to protect their patients' information dates back to the Hippocratic oath from the fourth century BC: "Whatever I see or hear in the lives of my patients, whether in connection with my professional practice or not, which ought not to be spoken of outside, I will keep secret, as considering all such things to be private." What was true then still rings true now, but we also have evidence that revealing some information is beneficial. Defining the right circumstances and the right manner for such legitimate privacy breaches is an ongoing debate within the profession that is also influenced by the evolution of values and priorities and the larger societal and judicial debates.

One of the particularly interesting features of the book is the process followed to produce it. In addition to the usual research and writing all authors engage in, the Milbank Foundation convened a 2-day discussion between the 3 authors and reviewers from aca- demia, public health and the world of politics. Central themes were clarified and refined for the reader's benefit through this remarkable collaborative process.

The book's only downside is that the "America" in the title refers almost exclusively to the United States of America. That said, the issues identified and lessons learned most certainly transcend both geographical borders and the scope of public health.

The debate about individual privacy rights versus the common good is timely and acutely vital. The rapidly evolving context of the 21 st century forces us to rearticulate how to sustain the enabling foundation of trust within our society. This book provides perspectives and insights from the past that will help inform future discussions across a full spectrum of issues. These range from the implementation of electronic health technology to the growing demands for information from governments and other health professionals; from the promising, yet ominous, rise of genetic testing to the growth of surveillance associated with public safety in our post-9/11 world. It can also help inform the current discussion within the worlds of public health and disease management.

\section{Alexandra Tcheremenska-Greenhill MD}

Family physician

Vancouver, BC

\section{REFERENCE}

1. Hippocratic oath [translated by North M]. Bethesda (MD): History of Medicine Division, National Library of Medicine, National Institutes of Heath 2002. Available: www.nlm.nih.gov/hmd/greek /greek_oath.html (accessed 2009 Jan. 28).

Dr. Tcheremenska-Greenhill is the Associate Chief Executive Officer of the British Columbia Medical Association in Vancouver, British Columbia, and serves on the board of the Canadian Society of Physician Executives. 